offer, particularly if their excavation is designed to test a particular astronomical hypothesis rather than simply to collect data. A long-standing proponent of this approach has been Euan MacKie, who in 1970 and 1971 excavated a structure at Kintraw, Argyll, claimed by Thom to be an observing platform. Although widely quoted, the evidence from the excavation was unfortunately inconclusive, as MacKie himself now admits. In this issue of Nature he and his co-authors discuss evidence from Minard - another site in Argyll where archaeological excavation was seen as testing an astronomical hypothesis. Perhaps the most striking result is that, unlike Kintraw, Minard indisputably has platforms that have been levelled by man; moreover, the main features at the site have been fairly securely radiocarbon dated to the mid-second millennium BC. Together, the various archaeological discoveries indicate that Minard was not a domestic, defensive, industrial or funerary site, but one intended, perhaps almost exclusively, for ritual use. Furthermore, both the striking distant horizon to the north-east, roughly in the direction of midsummer sunrise, and the general orientation of the site in this direction, seems to indicate that solar orientation was a deliberate and crucial function of the site.

Those interested in prehistoric astronomy will still have many questions to raise about the precise interpretation of Minard. In particular, many will dispute whether, on statistical grounds, the claim that it was used for high-precision observations (supporting Thom's 'calendrical' hypothesis) is really borne out. The northeastern horizon foresight does not fall

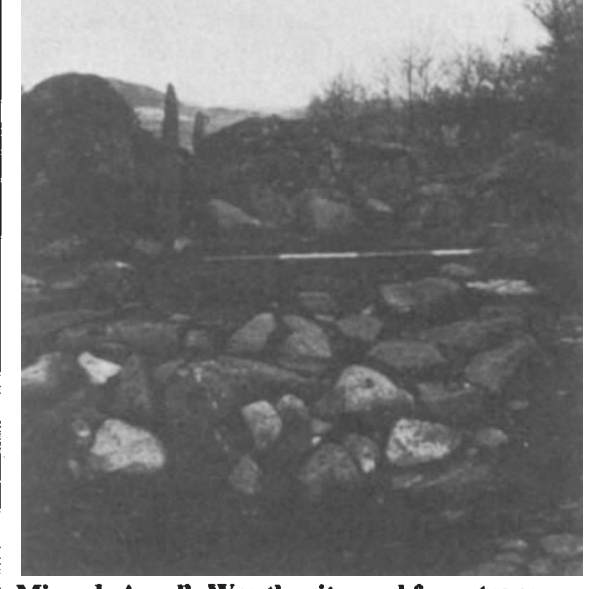

Minard, Argyll. Was the site used for astronomy in megalithic times?

exactly at the solstice, and any feature occurring within a few degrees of the solstitial position is susceptible to the 'halving the difference' argument used by MacKie et al. (viz). There are similar problems when defining the 'calendrical' equinox. Thus the evidence for high-precision astronomy is perhaps not as clear as MacKie's paper might lead us to believe; nonetheless Minard is surely destined to become an important site, evidence from which will generate considerable debate and, I hope, a few fresh hypotheses.

Clive Ruggles is in the Computing Studies Unit, University of Leicester, University Road, Leicester LEI 7RH, UK.

\title{
Genetic analysis
}

\section{Of man and mouse}

\section{from P.N. Goodfellow}

ON page 181 of this issue B. Robert et al. ${ }^{1}$ describe their determination of the chromosomal localization of the genes that code for several muscle proteins of the mouse. These results will engage those studying co-ordinate regulation of muscle proteins and those interested in the evolution of gene families. More importantly, by exploiting the species differences between Mus domesticus and Mus spretus, Robert et $a l$. introduce a new technique of mapping genes to chromosomes that may well become a standard tool for genetic analysis of the mouse.

The laboratory mouse has many advantages over man for genetic analysis, including a short generation time, plentiful genetic markers, and no restrictions on brother-sister or parent-child matings. So great were the advantages of working with mice that many geneticists believed that the proper study of man was mouse, a view which was encouraged by the development of inbred ${ }^{2}$, congenic $^{3}$ and recombinant-inbred strains ${ }^{4}$. Without these tools, it is doubtful whether many familiar systems, such as the genetics of transplantation and immune response, would yet have been unravelled.

Two advances have made the direct study of human genetics as profitable as the study of the mouse. First, the introduction of somatic cell techniques freed human genetics from the disadvantage of the long human life span and exploited the species differences between humans and rodents to provide genetic markers; using this method over $\mathbf{4 0 0}$ loci have been assigned, directly or indirectly, to human autosomes ${ }^{5}$, whereas only two or three had been assigned before the application of somatic cell genetics ${ }^{6}$. Second, in recent years, molecular biology has provided an almost limitless supply of genetic markers in the form of restriction fragment length polymorphisms (RFLP) defined by cloned
DNA probes (see ref. 7 for a recent review and ref. 8 for the latest advance). These markers have rejuvenated classical genetic approaches and have already contributed to the chromosomal localization of loci associated with muscular dystrophy ${ }^{9}$ and Huntington's disease ${ }^{10}$.

Mouse genetics has also benefitted from somatic cell techniques and molecular biology but because of the related origin of the common inbred mouse strains ${ }^{11,12}$ and the small number of strains available ${ }^{2}$, it more difficult in mouse than in man to find RFLPs that can be used as genetic markers. To overcome this deficiency, Robert et al. mated an inbred strain of the laboratory mouse, Mus domesticus, to an inbred strain of the related mouse, Mus spretus ${ }^{13}$. The two progenitors of the laboratory mouse, Mus musculus and Mus domesticus, have been separated from Mus spretus for about three million years ${ }^{14}$, which is sufficient time for there to have been enough divergence in DNA sequences to generate potential RFLPs in any cloned mouse gene.

In the wild, Mus domesticus and Mus spretus probably never mate with each other ${ }^{15}$, but, under carefully provided laboratory conditions, fertile female offspring can be produced ${ }^{13}$ and back-crossed to the parental strains ${ }^{16}$. (The male offspring of the between-species cross are infertile, as predicted by Haldane's law ${ }^{17}$ ). As demonstrated by Robert et al. for myosin alkali-light chain genes ${ }^{1}$, linkage between the RFLPs and other genetic markers can easily be followed in the back cross and used for gene mapping.

For some genetic studies, including deliberate mutagenesis, the mouse will always be the mammal of choice. Ethylnitrosourea can induce mutations at the incredibly high frequency of one mutant at each locus for every thousand offspring ${ }^{18}$. This means that saturation mutation mapping ${ }^{19}$ and the deliberate creation of mouse models for human disease are both feasible. Perhaps the proper study of man is both man and mouse.

1. Robert, B. et al. Nature 314, 181 (1985).

2. Festing, M.F.W. Inbred Strains In Biomedical Research (Macmillan, London, 1979).

3. Snell, G.D. J. Genet. 49, 87 (1948)

4. Bailey, D.W. Transpl. 11, 325 (1971).

5. Shows, T.B., McAlpine, P.J. \& Miller, R.C. Cytogenet. Cell Genet. 37, 340 (1984)

6. Renwick, J.H. Ann. Rev. Genet. 5, 81 (1972).

7. White, R. et at. Nature 313, 101 (1985).

8. Jeffreys, A.J., Wilson, V. \& Thein, S.L. Nature 314, 67 (1985).

9. Murray, J.M. et al. Nature 300, 69 (1982)

10. Gusella, J.F. et al. Nature 306, 234 (1983)

11. Ferris, S.D., Sage, R.D. \& Wilson, A.C. Nalure 295, 163 1. Ferris, $S$ (1982)

12. Vonekawa, H. et al. Differentiation 22, 222 (1982).

13. Bonhomme, F., Martin, S. \& Thaler, L. Experientia 34, 1140 (1978)

4. Ferris, S.D., Sage, R.D., Prager, E.M., Ritte, U. \& Wilson, A.C. Genetics 105, 681 (1983).

15. Britton, J. \& Thaler, L. Biochem. Genet. 16, 213 (1978)

16. Britton, J. \& Thaler, L. Biochem. Genet. 16, 213 (1978). Martin, S. C.r. Acad. Sci. Ser. D. 289, 545 (1979).

Martin, S. C.r. Acad. Sci. Ser. D. 289, S4,
7. Haldane, J.B.S. J. Genet. 12, 101 (1922).

18. Russell, W.L. el al. Proc. natl. Acad. Sci. U.S.A. 76, 5818 (1979).

9. Bode, V.C. Genetics 108, 457 (1984).

P.N. Goodfellow is at the Imperial Cancer Research Fund, P.O. Box 123, Lincoln's Inn Fields, London WC2A $3 P X$. 